\title{
Multi-Objective Optimization of HVAC Operation for Balancing Energy Use and Occupant Comfort in Educational Buildings
}

\author{
Alessandro Franco *(D), Carlo Bartoli, Paolo Conti ${ }^{(D)}$, Lorenzo Miserocchi ${ }^{(D)}$ and Daniele Testi $(D)$ \\ Department of Energy, Systems, Territory, and Constructions Engineering (DESTEC), University of Pisa, \\ Largo Lucio Lazzarino, 56122 Pisa, Italy; carlo.bartoli@unipi.it (C.B.); paolo.conti@unipi.it (P.C.); \\ lorenzo.miserocchi@gmail.com (L.M.); daniele.testi@unipi.it (D.T.) \\ * Correspondence: alessandro.franco@ing.unipi.it
}

Citation: Franco, A.; Bartoli, C.; Conti, P.; Miserocchi, L.; Testi, D. Multi-Objective Optimization of HVAC Operation for Balancing Energy Use and Occupant Comfort in Educational Buildings. Energies 2021, 14, 2847. https://doi.org/10.3390/ en14102847

Academic Editor: Miroslava Kavgic

Received: 22 April 2021

Accepted: 13 May 2021

Published: 14 May 2021

Publisher's Note: MDPI stays neutral with regard to jurisdictional claims in published maps and institutional affiliations.

Copyright: (C) 2021 by the authors. Licensee MDPI, Basel, Switzerland. This article is an open access article distributed under the terms and conditions of the Creative Commons Attribution (CC BY) license (https:// creativecommons.org/licenses/by/ $4.0 /)$.

\begin{abstract}
The paper provides a methodology for the optimal control of heating, ventilation, and air conditioning (HVAC) systems used in public buildings, with the purpose of obtaining high comfort and safety standards along with energy efficiency. The combination of the two concurrent objectives of minimizing energy use and guaranteeing high standards of occupant comfort is obtained by means of multi-objective optimization, in which a comfort model is combined along with a dynamic energy model of the building. The use of dynamic setpoints for the HVAC and the inclusion of comfort indicators represent a step forward, compared to the current design and operation procedures suggested by technical standards. The utilization of the proposed methodology is tested with reference to a case study, represented by an academic building used by the University of Pisa for educational purposes, whose extensive and variable occupancy can help to emphasize the importance of comfort in the operation of HVAC systems in different climatic conditions and with different occupancy profiles. We show how this optimization brings interesting results in terms of energysaving (up to $30 \%$ ), obtaining an increased comfort level (of more than $25 \%$ ) compared to the operating conditions suggested by technical standards.
\end{abstract}

Keywords: energy efficiency improvement; occupant comfort; HVAC operation; dynamic multiobjective optimization; shared smart buildings; sustainability goals

\section{Introduction}

The need to balance users' comfort, energy efficiency, and safety conditions in public buildings_-and in particular in educational ones - is highly relevant today. People spend the greatest part of their time indoors [1,2]. While this is strongly relative to the country/region of the world, the civil sector is responsible for about $40 \%$ of total energy consumption [3], and the educational sector represents a relevant amount of this portion [4]. This clearly requires in-depth analysis, in order to better handle the complex task of balancing these two concurrent objectives. Today, due to the COVID-19 pandemic, there are also stricter needs for maintaining high standards of indoor air quality in order to prevent airborne virus transmission, and this need brings with it new considerations about this specific topic.

While safety measures must be compliant with specific regulations, comfort and energy saving can be considered under different aspects, and a correct outline of the main elements of interest is necessary.

In the civil sector, specific attention must be paid to public buildings, as they involve interactions between users with different needs and different behaviors, leading to the need to develop reliable building control strategies in order to contemporarily achieve energy efficiency and comfort; in particular, this is relevant in buildings with educational purposes, such as campus university buildings. 
Considering the idea of pursuing energy saving and maintaining high indoor air quality standards, the attention paid to energy consumption by public buildings is well recognized today, as discussed in [5] and in several other papers available in the literature [6,7]. The comparison between the different targets must be evaluated in relation to the wide variety of public buildings (for commercial, educational, or other purposes), and with consideration of the different meteorological and occupancy-related conditions to which the building is subject. This requires the definition of accurate and easily manageable indicators: on the comfort side, both thermal comfort and indoor air quality have been widely discussed in the literature, and many indicators can be defined [8]; while on the energy efficiency side, a lot of different strategies can be used.

Considering comfort, the various models available can be divided into steady-state or adaptive models, where the latter fill the gap of a change in the level of occupants' metabolic activity that the former models cannot consider [9], while models for IAQ have been developed for many indoor air pollutants. For public buildings, such as educational buildings, in which the level of metabolic activity is almost constant and the main sources of pollutants are the buildings' users, the use of a steady-state model for thermal comfort and for the control of carbon dioxide concentration is widely accepted in technical standards $[10,11]$. Moreover, considering comfort, in the literature specific attention has been devoted to thermal comfort; in this case, indicators are presented in the form of a predicted percentage dissatisfied, according to the traditional Fanger's method [12]. Considering the problem of energy consumption and its control, the operation of lighting systems and of heating, ventilation, and air conditioning (HVAC) systems-including the possibility of using heat pumps (HP), a type of HVAC equipment that can provide both heat and cooling - appears to be particularly relevant. The energy consumption attributed to the HVAC system (for thermal and hygrometric control and air ventilation rate) often represents the main amount [13], whose demands are represented by the building's sensible and latent energy and ventilation demands. The calculation of building energy demands has been widely discussed, resulting in a wide variety of methodologies [14]. In general, a 1D physical model can be used without referring to more complex dynamic models [15]. Efficient control of most of the building's devices yields a global reduction of energy consumption, with a consequent reduction of emissions and energy bills [16].

Considering public buildings in general, educational buildings represent an important part of the public patrimony, as students attend schools for long periods; hence; good indoor comfort conditions must be guaranteed, with reduced energy use. Several works on the energy performance of educational buildings can be found in the literature. Dias Pereira et al. [17] provide a literature review on the energy use of schools worldwide, with the purpose of achieving energy benchmarks. The primary energy use of school buildings in European countries varies, according to different climatic conditions, from about 50 to $200 \mathrm{kWh} / \mathrm{m}^{2} /$ year. These values comprise all of the buildings' energy use (heating, cooling, and electricity). Elaboration of the data from [17] shows that in Italian educational buildings, energy use can be estimated in the range of $100-105 \mathrm{kWh} / \mathrm{m}^{2} /$ year, corresponding more or less to $34-35 \mathrm{kWh} / \mathrm{m}^{3}$. However, these values are average values that consider different climatic conditions and different use (some academic buildings are open from 8 a.m. to midnight, for example).

Considering the previous analysis, the aim of this study is the analysis of the conflicting targets during the operation of HVAC systems serving academic buildings, and their relationship with HVAC control parameters and meteorological and occupancy-related conditions [18]. Unlike technical standards, comfort will be considered to be a target instead of a constraint, and it will be counterposed against energy saving by means of a multi-objective optimization method. To this purpose, occupants' comfort will be evaluated considering thermal comfort and air quality, while energy saving will be evaluated by means of the ideal energy demands of the building, connected to the operation of the HVAC system. 
The presence and number of occupants will be placed at the center of the balancing of comfort and energy efficiency, by integrating it into the model for the optimal control of HVAC operating parameters. Since comfort is a target only when occupants are present in the building, a dynamic relationship between the two targets that considers comfort parameters only when occupants are present can be defined. This consideration can further lead to the definition of a relationship dependent not only on the number of occupants inside the rooms. It will be shown how the definition of a dynamic relationship, variable as a function of the number of occupants, can improve the achievement of both comfort and energy saving, simultaneously. The methodology proposed in this study has the peculiarity of being able to adapt to real-time conditions to ensure an optimal solution, since the relative importance of the targets is modified according to needs, and is dependent on the real occupation of the indoor spaces.

\section{The Problem of Balancing Energy Consumption and Comfort in Educational Buildings}

The purpose of the present study is to develop a methodology for controlling the operation of HVAC systems in educational buildings, focusing on both comfort and energy saving.

Occupants' comfort depends primarily on thermal comfort and air quality, while energy saving is evaluated by means of the ideal energy demands of the building, considering the operation of the HVAC system and of the other miscellaneous electric systems (MES) that are present in the building.

In general, comfort and energy saving represent two conflicting targets, because the need to maintain high standards of indoor air quality — mostly obtained via mechanical air ventilation and strict control of temperature, humidity, and indoor concentrations of pollutants, such as $\mathrm{CO}_{2}$, mainly during the cold and hot seasons-conflicts with the purpose of reducing energy consumption.

Considering ventilation, for example, this is recognized to be essential for the health and comfort of building occupants. It is well known that there is a qualitative link between pollutant concentration, ventilation rate, and energy demand, as described in Figure 1; consequently, there is often an apparent conflict between the desire to minimize ventilation rates, in order to reduce energy demand, and the desire to maximize ventilation, in order to ensure optimal indoor air quality.

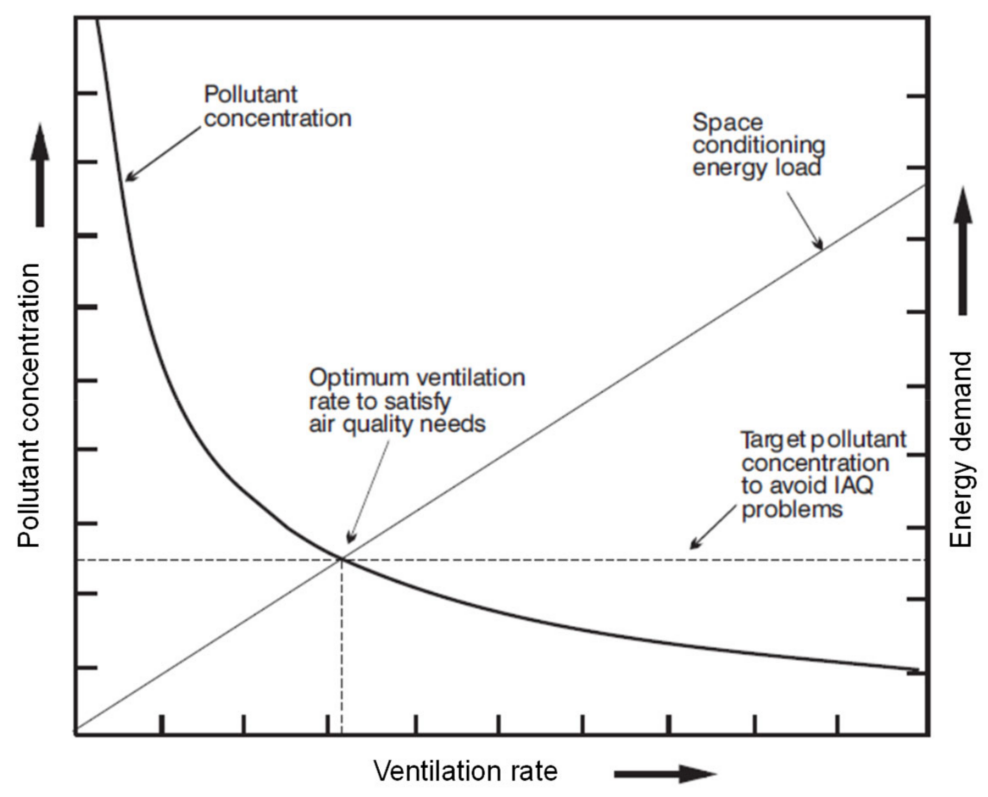

Figure 1. A qualitative connection between controlling pollutants and the energy demands of mechanical ventilation. 
Choice is dictated by local climate conditions or by building type and occupation. This concept can be extended to other comfort parameters, such as temperature, humidity, and luminance. The contraposition between comfort and energy efficiency has already been analyzed in previous literature focusing both on domestic and public buildings, and is very important in the control of smart buildings [19]. The results of these studies are commonly presented in the form of a Pareto frontier, which represents the locus of points that have the optimal characteristics—as in [20] — for overall comfort and energy consumption. Every point that belongs to this frontier is a direct consequence of a different choice for the relative importance of the involved objectives and, thus, it is interesting not only as a member of the frontier, but also because of the specific condition from which it derives. To this purpose, a sensitivity analysis must be conducted, investigating the effects of the relative importance of occupants' comfort and energy saving, both on the targets themselves and on HVAC control parameters.

Current design and operation procedures suggested by technical standards, which are evaluated based on a typical occupancy [11], do not consider variation and the consequences this has both on energy efficiency and comfort. These many aspects are summarized in [12], in which the "human dimension" in buildings is considered in every moment of the building's life cycle, from design to operation and management. The modelling of stochastic profiles instead of static ones has been proven to be necessary for assessing building energy performance, especially in buildings with closer interactions between the users and the building itself [21].

Today, the problem of balancing internal comfort and energy saving has also been complemented-after the relevant experience of the COVID-19 pandemic-with an accurate control of the indoor environment in order to prevent airborne virus transmission [22]. In fact, some different parameters can be considered for the risk of transmission in indoor spaces: among those, ventilation (natural or mechanical) and humidity show direct correlation with the operation of HVAC systems, and so with energy consumption. New approaches for designing or upgrading HVAC systems are necessary in order to make indoor spaces safe without compromising on energy efficiency. The installation of instruments for indoor air quality monitoring is paramount, together with the implementation of building management and control systems. While quantification of the first two elements (comfort and energy consumption) is possible, the last element poses more difficulty, such that it cannot be directly considered in an optimization strategy, even if it determines constraints for the operation of the system. In the next subsections we will discuss the problems of defining the elements for quantification of energy consumption, and of the comfort index, focusing the attention on possible methods of balancing the two objectives, whose main aspects are linked to one another by the means of relevant parameters (as shown in Table 1).

Table 1. The problem of balancing occupants' comfort and energy use in buildings.

\begin{tabular}{ccc}
\hline Comfort and Safety & Relevant Parameters & Energy Efficiency \\
\hline Thermo-hygrometric comfort & Temperature and relative humidity & HVAC operation \\
Indoor air quality & Pollutants' concentration & HVAC operation \\
Visual comfort & Illuminance & Lighting system \\
Acoustic comfort & Noise & Acoustic insulation \\
Services & Other parameters & MES, DHW, BACS, etc. \\
\hline
\end{tabular}

\subsection{Building Energy Consumption}

The energy consumption of public buildings and of educational buildings can be primarily referred to the operation of their HVAC systems and lighting systems. Due to advances in lighting systems, with the reduced power requirements of the individual lights (reduced from the order of $100 \mathrm{~W}$ to $1-5 \mathrm{~W}$ thanks to the recent development of LED technology), a considerable amount of this energy is used to provide thermal and air quality comfort (heating, cooling, and ventilation). 
The energy required for HVAC operation can be connected to the local climatic conditions (external air temperature and relative humidity) and to the specific type of activity conducted in a given building (commercial, service, educational, etc.). Moreover, energy consumption can be directly correlated with the occupancy profile of a building. The energy demands of a public building, depending mainly on meteorological and occupancy conditions, are connected with sensible energy demand, latent energy demand, and ventilation rate. Thus, it is important to define the required internal temperature and humidity conditions, and to predict the external temperature and the occupancy profile of the building. In the following considerations we will refer in general to a generic HVAC system (Figure 2).

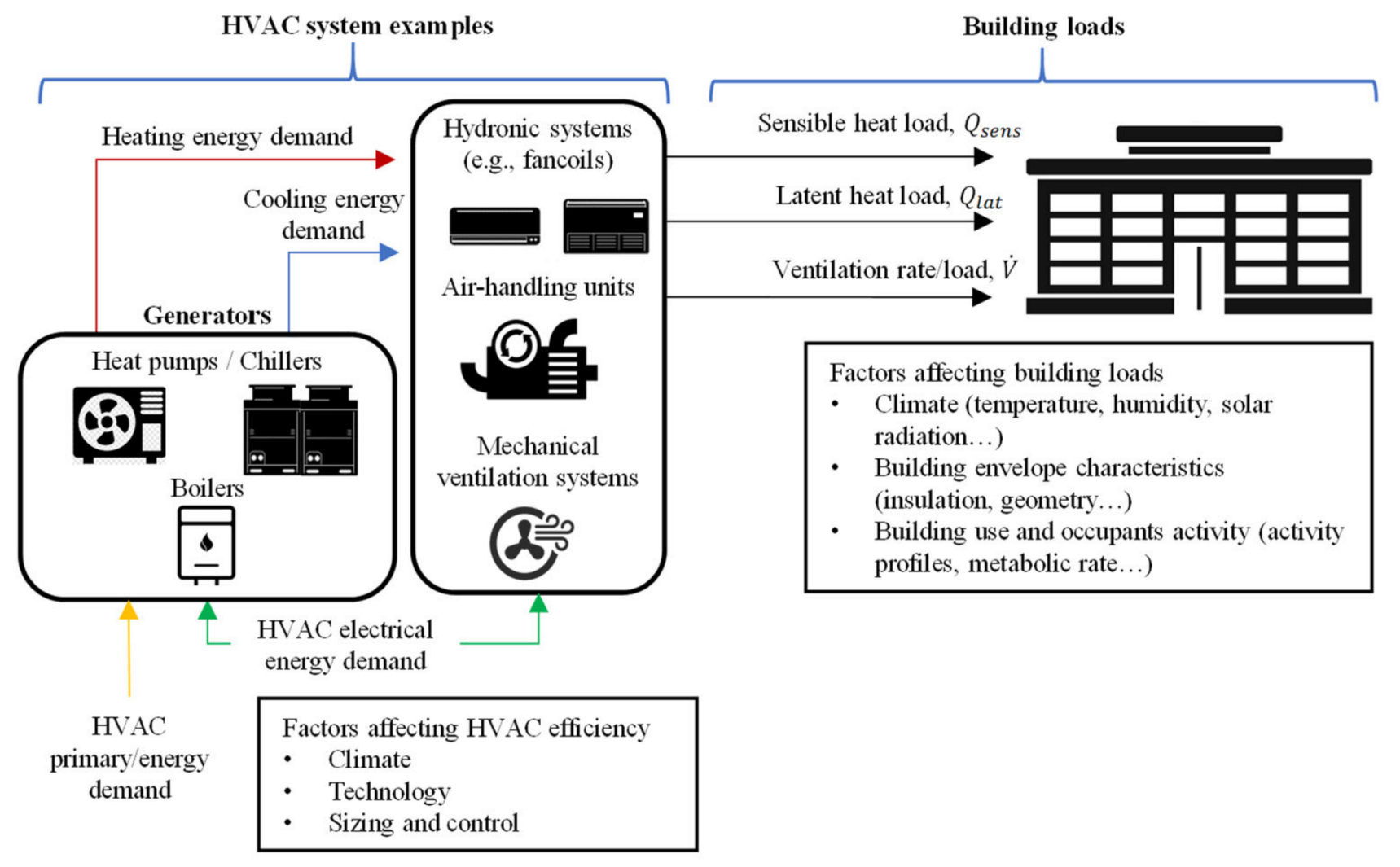

Figure 2. HVAC systems and typical energy flows (schematic).

\subsubsection{HVAC Energy Demand for Sensible Heat}

A relevant term of energy consumption for the operation of HVAC systems is represented by the energy demand for sensible heat. This is necessary for both heating and cooling. It refers to the need to maintain a target value for internal temperature (e.g., $18-20{ }^{\circ} \mathrm{C}$ in winter or $24-26^{\circ} \mathrm{C}$ during the summer period). The sensible energy demand can be evaluated by the knowledge of weather forecasts and of the occupancy profile, according to standard methodologies [16], or by the energy-signature method [23].

\subsubsection{HVAC Energy Demand for Latent Heat}

Considering latent energy demand, this is mainly connected to dehumidification demands, operated with the purpose of maintaining imposed values of relative humidity inside the building (40-60\%). This aspect is directly connected with the climatic conditions and with the effective number of occupants. In some specific cases, in mid-climate conditions, latent energy demands can become more relevant than sensible heat demands, mainly during mid-seasons and when the occupation of indoor spaces is quite high [18]. 


\subsubsection{HVAC Energy Demand for Ventilation}

Considering energy consumption due to ventilation rate, this is connected to the effective occupancy of the building in general or of a specific room. A better air quality level requires a higher ventilation rate. Limit values for carbon dioxide concentration determine the ventilation demand. Occupancy can be evaluated in connection with carbon dioxide monitoring, which has been proven to be a reliable method [24,25]. Considering the problem of COVID-19, it is expected that the amount of energy required for ventilation rates would increase in a relevant way, according to the specific regulations imposed to reduce recirculation rates.

\subsection{Building Internal Comfort}

Considering comfort, both thermal comfort and indoor air quality indicators have been widely discussed in the literature, and many indicators have been defined. As previously stated, the coupling of these aspects into a single indicator for comfort is still an open problem, which merits further investigation. In the literature, thermal comfort can usually be referred to Fanger's model [12]. In this model, the comfort index is represented by a predicted percentage dissatisfied (PPD). This index is linked to the predicted mean vote (PMV), depending on the combination of several variables-namely, metabolic rate, clothing, air temperature, mean radiant temperature, relative humidity, and air speed. Concerning the air quality model, we can obtain and define an index comparable to the thermal comfort index, in order to easily determine a global comfort index. In this case, the predicted percentage dissatisfied can be connected to the distance from relevant indicators of indoor air quality, such as $\mathrm{CO}_{2}$ concentration.

\section{The "Building System" and the Proposed Optimization Method}

The multi-objective optimization method proposed in the present paper is articulated in different parts, as outlined in Figure 3. The first part is represented by the building model and, consequently, the model for energy demand calculation; this model, starting from the knowledge of the characteristics of the building, level of occupancy, and specific climatic conditions, allows us to evaluate the energy consumption requirements of both the lighting system and the HVAC operation. In this case, it can be used for the determination of the sensible and latent energy requirements, and to define the required ventilation rate, satisfying the specifications of both the thermal comfort model and of air quality comfort. On the left side of the scheme, there are the input variables for the models, shown inside light blue rounded rectangles; these represent the external and internal conditions of the building. They consist of meteorological variables, variables connected to lighting, and occupancy profiles. They feed the building and energy calculation models, and occupancy also feeds the ventilation rate model. The setpoints of internal temperature, relative humidity, and carbon dioxide concentration represent HVAC control parameters, and are shown in green circles. In particular, the $\mathrm{CO}_{2}$ setpoint is involved in the ventilation rate and air quality models, while temperature and humidity are connected to the building and energy calculation models and to the thermal comfort model.

Let us start by describing the building model, including the model for energy calculation. This consists of a resistance-capacitance thermal network, which models the building through several nodes for the envelope and one node for the indoor air, assumed as a single thermal zone [15]. Opaque capacitive walls are modeled as a series of multiple resistance-capacitance nodes, while glazed elements are modeled as purely resistant bodies. The following energy exchanges are considered: the conductive heat transfer among the capacity layers of opaque walls; the convective and the radiant long-wave heat transfer between the envelope surfaces and the indoor/outdoor environments; radiant long-wave heat transfer with the sky; absorption of solar radiation; radiant long-wave heat transfer among internal surfaces; and radiant long-wave heat transfer with internal gains (e.g., occupants). The sensible energy demand of the internal air node is calculated accounting for all of the mentioned energy exchanges, ventilation fluxes, and internal gains using an 
hourly timestep. The latent energy demand is evaluated through the vapor mass balance of the indoor air. The energy demand calculation model is based on the balance of the air node of the thermal network, and calculates latent energy demands by means of a vapor mass balance. The model for the determination of the ventilation rate is based on the balance of carbon dioxide concentration within the control volume, and considers human breathing, which acts as a source with a production rate of $0.3 \mathrm{~L} / \mathrm{min}$ per person, and natural and mechanical ventilation, which acts by means of the renewal of ambient air with external air at a concentration of $400 \mathrm{ppm}$ :

$$
\mathrm{V} \frac{\mathrm{dC}_{\mathrm{CO}_{2}}(\mathrm{t})}{\mathrm{dt}}=\dot{\mathrm{r}} \mathrm{n}_{\mathrm{occ}}-\dot{\mathrm{V}}\left(\mathrm{C}_{\mathrm{CO}_{2}}(\mathrm{t})-\mathrm{C}_{\mathrm{CO}_{2}, \mathrm{ext}}\right)
$$

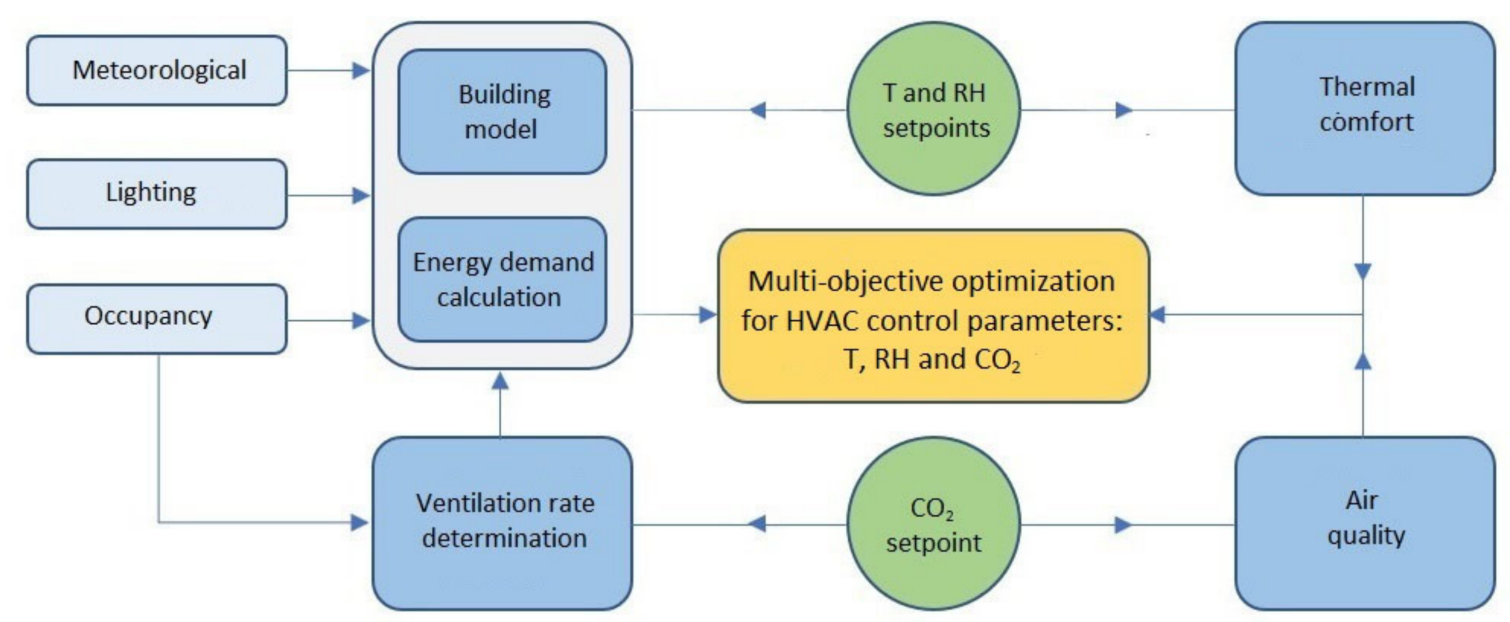

Figure 3. Multi-objective optimization: overall methodological scheme.

Next, this model operates the discretization of the time derivative, and allows us to obtain the required ventilation rate for maintaining the value of carbon dioxide concentration under the desired value. The thermal comfort model used is Fanger's model [12], which presents the predicted percentage of dissatisfied (PPD) as the index for evaluating thermal comfort. As mentioned, this index is linked to the predicted mean vote (PMV). According to Fanger's model, the relationship between PMV and PPD is given by:

$$
\operatorname{PPD}_{\mathrm{TH}}=100-95 \exp \left(-0.03353 \mathrm{PMV}^{4}-0.2719 \mathrm{PMV}^{2}\right)
$$

The air quality model has been realized within this study, and is aimed at finding an index that can be comparable to the thermal comfort one, in order to easily determine a global comfort index. For these reasons, according to a model like Fanger's, the predicted percentage dissatisfied can be defined considering the difference in $\mathrm{CO}_{2}$ concentration, expressed in ppm, with respect to a reference value, assumed in this case as $400 \mathrm{ppm}$ (the $\mathrm{CO}_{2}$ concentration of the external air). Hence, the indicator defining the percentage dissatisfied with respect to the $\mathrm{CO}_{2}$ indicator is defined as:

$$
\mathrm{PPD}_{\mathrm{IAQ}}=\alpha-(\alpha-5) \exp \left(-\beta\left(\frac{\mathrm{C}_{\mathrm{CO}_{2}}-\mathrm{C}_{\mathrm{CO}_{2}, \mathrm{ext}}}{\mathrm{C}_{\mathrm{CO}_{2}, \mathrm{ext}}}\right)^{4}\right)
$$

Equation (3) gives the maximum value for the predicted percentage dissatisfied, always considering $5 \%$ dissatisfaction, as in Fanger's model; $\beta$ is a factor that helps shape the form in order to obtain the desired percentage in relation to determined $\mathrm{CO}_{2}$ concentrations. In this case, $\alpha$ has been set at 25 to represent the idea that indoor air quality is less important than thermal comfort in a building in which the occupants are mostly 
stationary; while $\beta$ has been set at 0.05 , in order to attain the values of $6 \%$ at $800 \mathrm{ppm}, 16 \%$ at $1200 \mathrm{ppm}$, and almost $25 \%$ at $1600 \mathrm{ppm}$, which are the values for the IAQ classes that will be discussed later.

For combining the two aspects considered into one indicator, the choice has been to define an overall predicted percentage dissatisfied in order to preserve Fanger's model, which considers only thermal comfort. This can be done in many ways, two of which are presented here:

$$
\begin{gathered}
\mathrm{PPD}_{\text {tot }}=\left\langle\mathrm{PPD}_{\mathrm{TH}}\right\rangle+\left\langle\mathrm{PPD}_{\mathrm{IAQ}}\right\rangle=1-\left(1-\mathrm{PPD}_{\mathrm{TH}}\right)\left(1-\mathrm{PPD}_{\mathrm{IAQ}}\right) \\
\mathrm{PPD}_{\text {tot }}=\frac{\mathrm{PPD}_{\mathrm{TH}}+\mathrm{PPD}_{\mathrm{IAQ}}}{\max \left(\mathrm{PPD}_{\mathrm{TH}}\right)+\max \left(\mathrm{PPD}_{\mathrm{IAQ}}\right)}=\frac{\mathrm{PPD}_{\mathrm{TH}}+\mathrm{PPD}_{\mathrm{IAQ}}}{100+\alpha}
\end{gathered}
$$

In Equation (4) the indexes are summed as probabilities and the maximum value of 1 is clearly noticeable, while in Equation (5) they are summed as percentages and a correction factor is needed in order to attain a maximum value of 1 . However, in Fanger's model, the PPD index does not represent an uncertainty, so the formula in Equation (5) will be used.

\subsection{Multi-Objective Optimization Method for HVAC Operation}

The optimization of HVAC systems relies upon the development of an optimized strategy based on the utility function method.

This is one of the methods for the multi-objective optimization discussed in the textbook [26]. As schematically shown in Figure 4, this method is based on the definition of the control variables and their acceptable ranges, the definition of an indicator for each target, and the definition of the utility function as a weighted sum of these indicators.

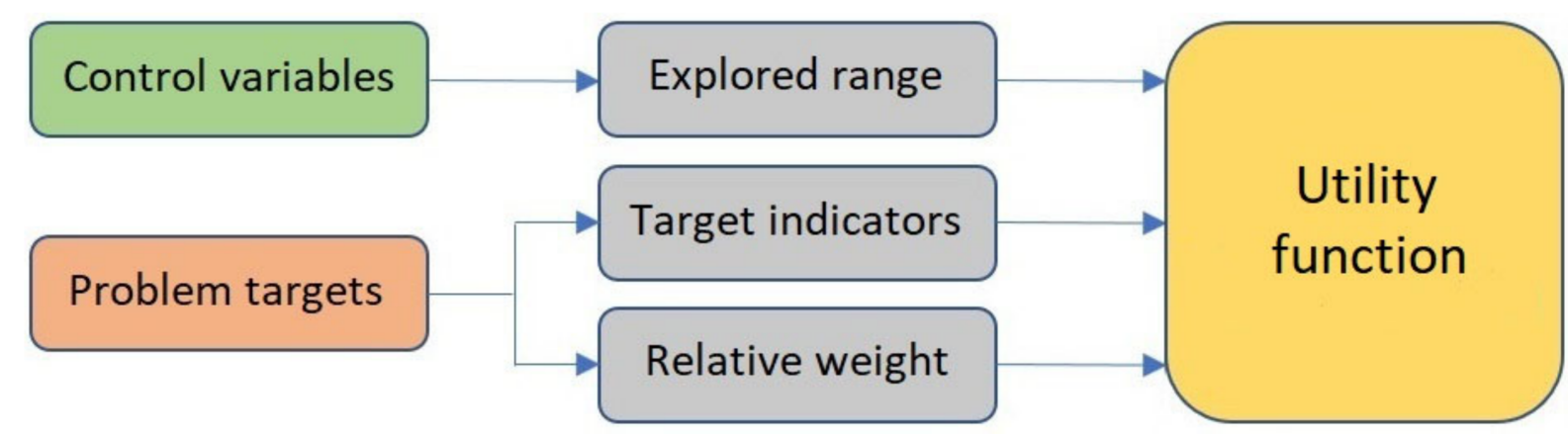

Figure 4. Definition of utility function for the multi-objective optimization.

Temperature has been chosen to range from $18{ }^{\circ} \mathrm{C}$ to $30^{\circ} \mathrm{C}$ in increments of $1{ }^{\circ} \mathrm{C}$, so as to be valid for both heating and cooling. Relative humidity has been chosen to range from $40 \%$ to $60 \%$ in increments of $5 \%$, so as to remain in the optimal range for human health. Carbon dioxide concentration has been divided in three IAQ classes represented by their maximum acceptable values: 800, 1200, and 1600 ppm, respectively. These classes are equally spaced and represent a range wider than the one commonly used in technical standards [11], so as to verify the fairness of the air quality index proposed.

For the comfort indicator, the normalization of the overall comfort index presented in Equation (5) has been chosen:

$$
\mathrm{f}_{\text {comf }}=\frac{\mathrm{PPD}_{\text {tot }}-\min \left(\mathrm{PPD}_{\text {tot }}\right)}{\max \left(\mathrm{PPD}_{\text {tot }}\right)-\min \left(\mathrm{PPD}_{\text {tot }}\right)} \quad \mathrm{PPD}_{\text {tot }}=\frac{\mathrm{PPD}_{\mathrm{TH}}+\mathrm{PPD}_{\mathrm{IAQ}}}{100+\alpha}
$$

For the energy saving indicator, the normalization of the absolute sum of each part of the energy demand has been chosen:

$$
\mathrm{f}_{\text {cons }}=\frac{\mathrm{Q}_{\text {tot }}-\min \left(\mathrm{Q}_{\text {tot }}\right)}{\max \left(\mathrm{Q}_{\mathrm{tot}}\right)-\min \left(\mathrm{Q}_{\mathrm{tot}}\right)} \quad \mathrm{Q}_{\text {tot }}=\left|\mathrm{Q}_{\text {sens }}\right|+\left|\mathrm{Q}_{\text {lat }}\right|
$$


A method for the multi-objective optimization of the HVAC system, permitting the combination of the two different objectives, is the "utility function method" [26]. In this case, a specific indicator obtained as a weighted sum of the two objectives defined by Equations (6) and (7) can be assumed as an objective function of the optimal design:

$$
\mathrm{f}=\mathrm{w}_{\text {comf }} \mathrm{f}_{\text {comf }}+\mathrm{w}_{\text {cons }} \mathrm{f}_{\text {cons }}
$$

Considering the function defined by Equation (8), the terms $\mathrm{w}_{\text {comf }}$ and $\mathrm{w}_{\text {cons }}$ define the relative importance of the two different objectives of comfort and energy saving, respectively; the two weights range from 0 to 1 , and their sum is 1 .

\subsection{Choice of the Target Weights}

The choice of the values for $\mathrm{w}_{\text {comf }}$ and $\mathrm{w}_{\text {cons }}$ directly represents the relative importance of the two different targets. The effects that this choice has on both the targets and on the HVAC control parameters need to be discussed. Let us consider the involved targets and their relation to the building's occupancy. Since comfort is important only when the building is occupied, a dynamic weight could be defined, based on the building's schedule, assuming a value shifted to energy saving when the building is predicted to be unoccupied. With the monitoring of occupants, which guarantees the knowledge of the number of occupants at every time, the dynamicity of the weighting can be further improved, by defining a weight dependent not only on the presence or absence of occupants, but also on their number. In this study, a linear relation has been proposed:

$$
\left\{\begin{array}{c}
\mathrm{w}_{\mathrm{comf}}(\mathrm{t})=0.2 \text { if } \mathrm{n}_{\mathrm{occ}}=0 \\
\mathrm{c}_{\mathrm{comf}}-\mathrm{b}_{\mathrm{comf}}\left(\frac{1}{2}-\frac{\mathrm{n}_{\mathrm{occ}}(\mathrm{t})}{\max \left(\mathrm{n}_{\mathrm{occ}}\right)}\right) \text { if } \mathrm{n}_{\mathrm{occ}}>0
\end{array}\right.
$$

In Equation (9), $c_{\text {comf }}$ represents the reference value (center), and $b_{\text {comf }}$ is the bandwidth of the dynamic weight. This adds degrees of freedom to the definition of the weights in the optimization procedure, as the values of both the center and the bandwidth must be chosen, and so it helps to define the correct control strategy for each building considered.

\section{Application of the Methodology to a Test Case}

In order to test the method proposed in the present study, a particular academic building was analyzed (an aerial photograph is provided in Figure 5). The building is situated in Pisa (1694 Heating Degree Day) and is used by the University of Pisa throughout the year for lessons, exams, and other activities. Reference outdoor climate data are presented in Table 2 [27].

\begin{tabular}{|c|c|c|c|c|c|c|c|c|c|c|c|c|c|}
\hline & Jan & Feb & Mar & Apr & May & Jun & Jul & Aug & Sep & Oct & Nov & Dec & Year \\
\hline $\mathrm{T}_{\mathrm{avg}}\left({ }^{\circ} \mathrm{C}\right)$ & 7.3 & 7.4 & 10.7 & 12.9 & 17.9 & 20.6 & 22.9 & 23.1 & 19.8 & 15.6 & 11.7 & 7.6 & 14.8 \\
\hline $\mathrm{G}\left(\mathrm{kWh} /\left(\mathrm{m}^{2} \mathrm{~d}\right)\right)$ & 1.6 & 2.3 & 3.3 & 4.3 & 5.9 & 6.4 & 6.8 & 5.9 & 4.4 & 2.6 & 1.9 & 1.4 & 3.9 \\
\hline Outdoor RH (\%) & 85.0 & 74.8 & 79.8 & 78.9 & 74.4 & 74.2 & 71.5 & 76.6 & 81.5 & 86.2 & 78.3 & 85.8 & 79.0 \\
\hline $\begin{array}{l}\text { Wind velocity } \\
(\mathrm{m} / \mathrm{s})\end{array}$ & 1.8 & 1.5 & 1.3 & 1.6 & 1.9 & 1.6 & 1.7 & 1.3 & 1.0 & 1.4 & 1.6 & 2.1 & 1.6 \\
\hline
\end{tabular}

Table 2. Reference climatic data for Pisa.

We chose this type of building for its extensive occupancy, which can help in emphasizing the importance of comfort in the operation of HVAC systems. The considered building has a surface of $1925 \mathrm{~m}^{2}(35 \mathrm{~m} \times 55 \mathrm{~m})$, a total available volume of approximately $10,000 \mathrm{~m}^{3}$, and is oriented 24 degrees North, as clearly evidenced in Figure 5. 

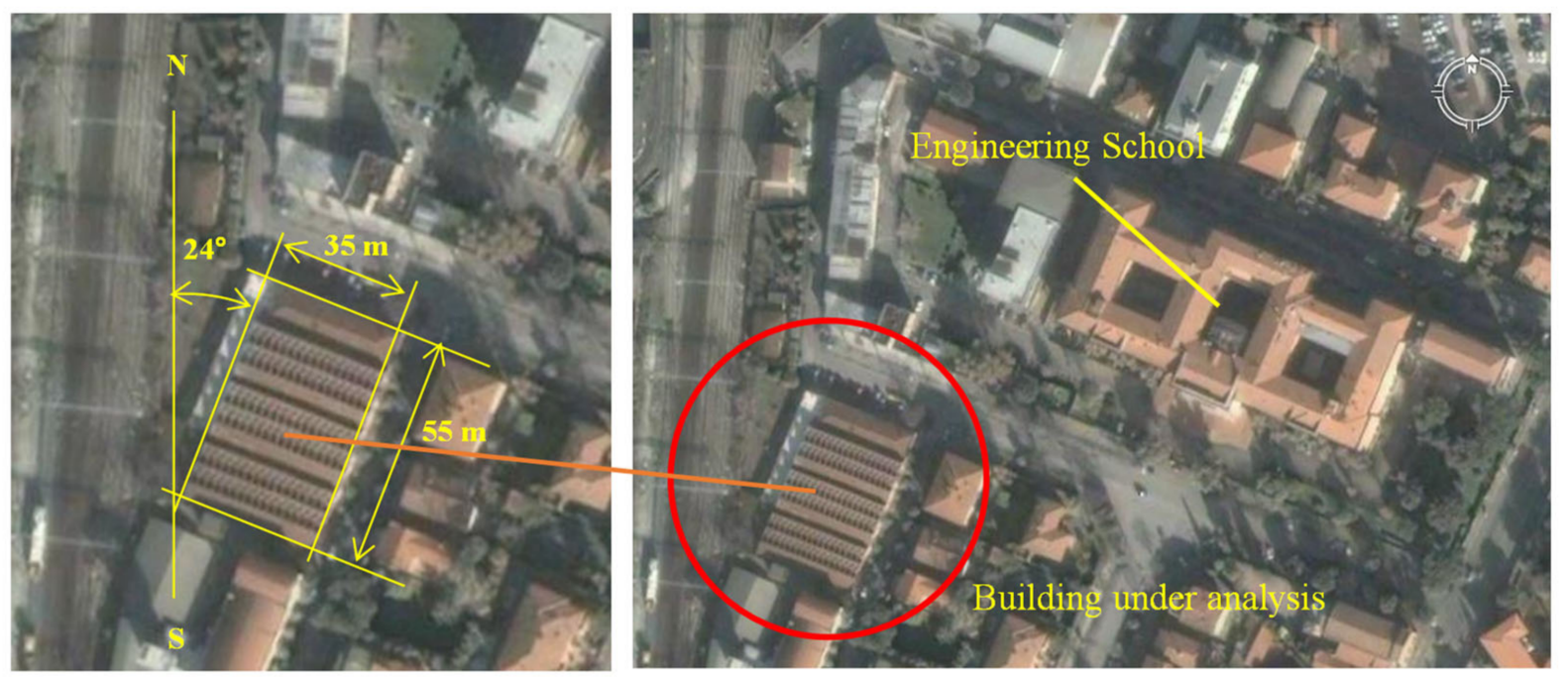

Figure 5. The building considered for testing the optimization method (an aerial view).

The external building surface is approximately $5500 \mathrm{~m}^{2}$ (both opaque and glazed), corresponding to an aspect ratio surface/volume of about $0.55 \mathrm{~m}^{-1}$. The building has stone walls with face bricks and a reinforced concrete structure, which results in a thermal resistance of about $1 \mathrm{~m}^{2} \mathrm{~K} / \mathrm{W}$. The saw-tooth roof includes $500 \mathrm{~m}^{2}$ of single-glazed windows, with a thermal transmittance of about $5 \mathrm{~W} /\left(\mathrm{m}^{2} \mathrm{~K}\right)$ and a solar heat gain coefficient of 0.8 . There are no other glazed elements on the vertical walls. The building was normally used 7 days per week (including Sundays) and from 8 a.m. to midnight, excluding some holiday periods ( 3 weeks in August, 1 week during the Christmas holidays, and 3 days during the Easter holidays).

Inside the building there are 9 classrooms which provide 1388 seats. The geometric characteristics of the 9 classrooms are reported in Table 3; as can be seen, they have almost the same surface area to volume ratio of about $5.6 \mathrm{~m}^{3} / \mathrm{m}^{2}$ (only 1 of the 9 classrooms-the one identified as number 9 in Table 3 -is different).

Table 3. The geometric characteristics of the nine classrooms in the selected building.

\begin{tabular}{|c|c|c|c|c|c|}
\hline Classroom & $\begin{array}{c}\text { Maximum } \\
\text { Occupation, } \\
\text { N ( ) }\end{array}$ & $\begin{array}{c}\text { Floor } \\
\text { Surface, A } \\
\left(\mathrm{m}^{2}\right)\end{array}$ & $\begin{array}{c}\text { Volume, } \mathrm{V} \\
\left(\mathrm{m}^{3}\right)\end{array}$ & $\begin{array}{c}\text { Ratio V/A } \\
\left(\mathrm{m}^{3} / \mathrm{m}^{2}\right)\end{array}$ & $\begin{array}{c}\text { Minimum } \\
\text { Volume per } \\
\text { Student, V/N }\left(\mathrm{m}^{3}\right)\end{array}$ \\
\hline 1 & 309 & 286 & 1587 & 5.55 & 5.14 \\
\hline 2 & 208 & 216 & 1220 & 5.65 & 5.87 \\
\hline 3 & 196 & 197 & 1094 & 5.55 & 5.58 \\
\hline 4,5 & 104 & 129 & 717 & 5.56 & 6.89 \\
\hline $6,7,8$ & 109 & 128 & 711 & 5.55 & 6.52 \\
\hline 9 & 140 & 131 & 439 & 3.35 & 3.14 \\
\hline
\end{tabular}

The occupancy of the building in the typical pre-COVID-19 scenario was organized into four periods, two trimesters of lessons (March-May and October-December), and three periods of exams (January-February, June-July, and September), which are characterized by different occupancies, with higher levels occurring during the period of lessons from October to December.

The reference energy demand of the building was evaluated using the above-mentioned thermal network model, considering the local typical meteorological year (see Table 2), the "effective" hourly occupancy, and internal air setpoints equal to $20{ }^{\circ} \mathrm{C}$ and $26^{\circ} \mathrm{C}$ in winter and summer operation, respectively. The obtained yearly demands were $443 \mathrm{MWh}$ ( 230 kWh per floor surface) for heating, 22 MWh ( 11 kWh per floor surface) for cooling, and $42 \mathrm{MWh}(\sim 21 \mathrm{kWh}$ per floor surface) for dehumidification. For this type of building, in 
which the consequences of uncomfortable environmental conditions would affect a high number of occupants, while an energy-intensive environment would lead to high energy consumption due to both high specific consumption and large surface area, the chosen a reference value for the center was $c_{\text {comf }}=0.5$, which represents the choice to not favor either of the two objectives. As for the bandwidth, a sensitivity analysis was performed, but the reference value considered was $b_{\text {comf }}=0.2$, unless differently specified, which represents limited changes, so as to avoid excessive penalization of one objective or the other.

\section{Results of the Application of the Optimal Design Strategy and Discussion}

The method described in Section 3 was been applied and tested on the building previously described, in order to appreciate the possible improvements in terms of energy saving and increase of users' comfort perception. For this reason, an accurate prediction of climatic conditions and of building occupation profiles is fundamental. Considering the specific use of the building, the predicted daily number of occupants is clearly based on the period of operation of the building. The differences can relate to the specific activity conducted inside (lessons, examination) or the presence profile; for the latter case, two additional conditions can be established: weekends (days in which the building operates, but a reduced number of students is inside for personal activity), and closed days. The period of lessons consists of 24 weeks in the year; at 5 days every week, a total of 122 days are considered. The period of examination consists of 10 weeks (70 days). The remaining 173 days are weekends (Saturdays and Sundays and working days without examinations or lessons) or closed days (August, Christmas and Easter holidays, and other public holidays), which make up 116 and 57 days, respectively. Considering this clustering, and using the previously described energy model, the daily sensible energy demand shows a good linear trend with respect to the daily mean temperature difference between the inside and the outside; this correlation also leads to small forecasting errors in the energy requirements in both the heating period (positive values) and the cooling period (negative values are reported), as reported in Figure 6. In Figure 6a, the daily sensible energy demand is shown as a function of the daily mean temperature difference, and in Figure $6 \mathrm{~b}$, the predicted daily number of occupants is sorted in ascending order.

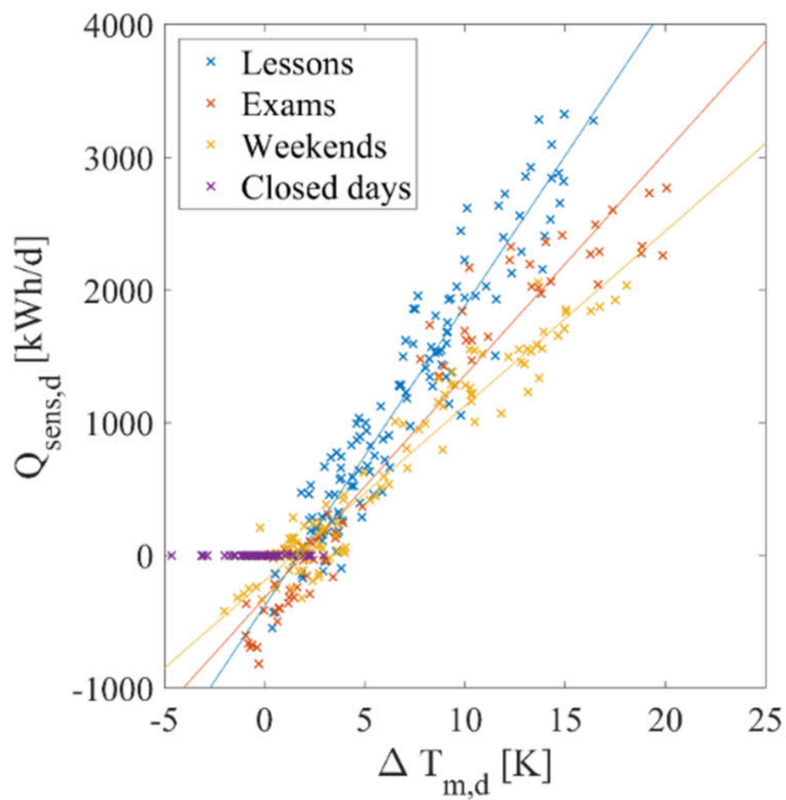

(a)

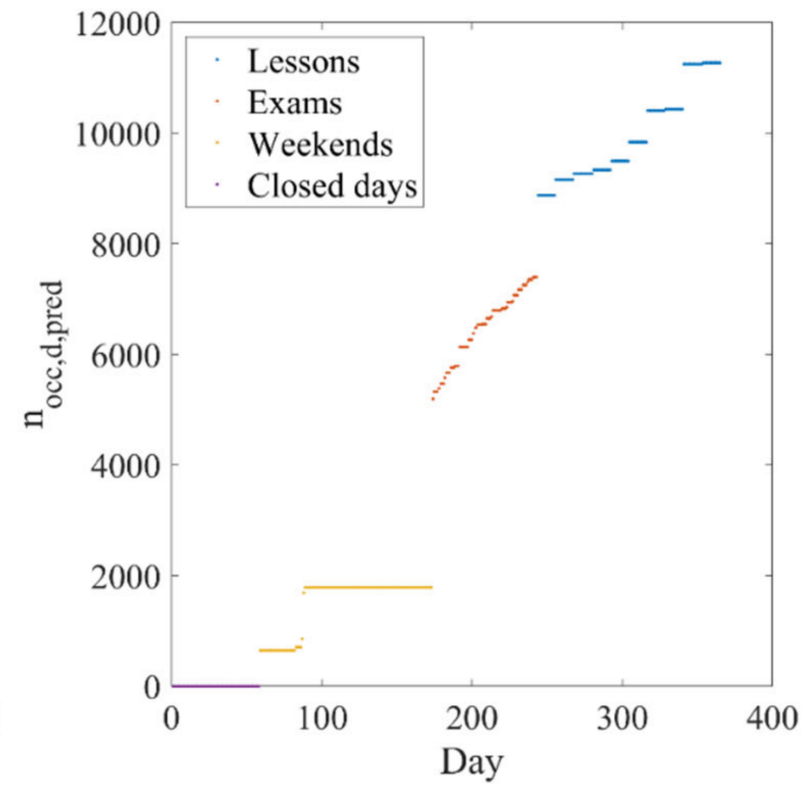

(b)

Figure 6. Correlation between daily sensible energy demand and the difference between indoor and outdoor temperature (a); predicted daily number of occupants for different clusters (b). 
Moving to latent energy demand, let us consider only dehumidification demand, for it has greater importance than that of humidification. The results of this specific analysis are provided in Figure 6 . In this case, only three clusters are considered, excluding the "closed days".

In particular, in Figure 7a, the daily dehumidification energy demand is shown, represented as a function of the predicted daily number of occupants, while in Figure $7 \mathrm{~b}$, the results of an analysis conducted using the k-means clustering algorithm [28] are presented. It is clearly noticeable that clustering according to the period of the year and to weekends is paramount for forecasting purposes. The quality of clustering is here defined by means of the silhouette index [29], which evaluates whether the positioning of a certain element in its cluster is correct or not.

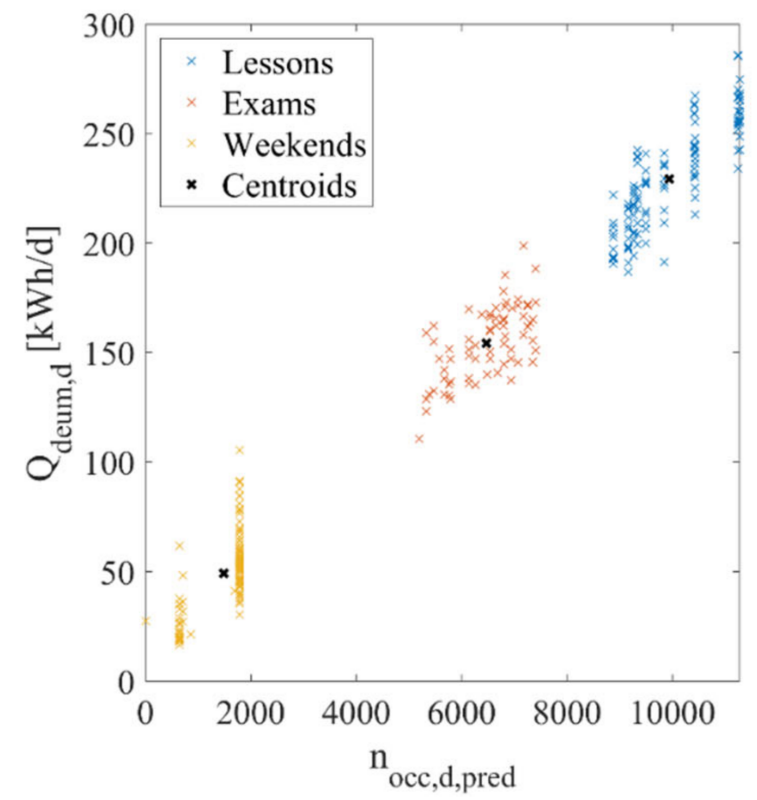

(a)

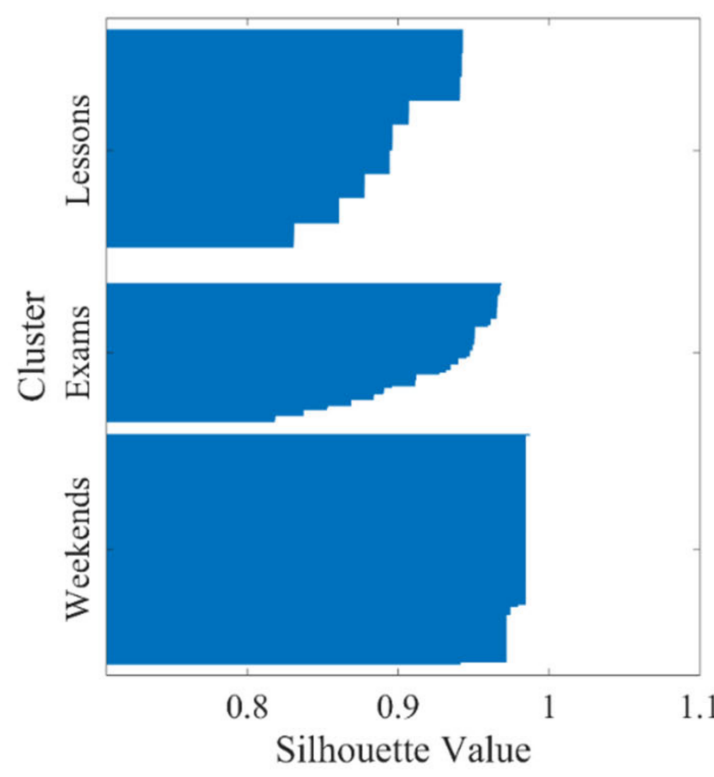

(b)

Figure 7. Daily energy demand for dehumidification vs. predicted daily number of occupants (a); silhouette index for clusters representing three different kinds of day $(\mathbf{b})$.

Finally, we can consider the energy consumption connected to ventilation rates. In this case, dividing the days into different clusters has a reduced significance, while the analysis of hourly results is more interesting. The ventilation rate can be represented as a function of the air quality class and of the predicted and "effective" occupancy, as provided in Figure 8a,b, respectively.

The analysis of the data reported in Figure 8 clearly shows a correlation between ventilation rate and occupancy, especially if the latter can be effectively monitored. It is shown that a better class of air quality requires a greater ventilation rate, and vice versa. It is also shown how the worst air quality class is seldom allowed, which demonstrates that the air quality index proposed provides correct penalties to unacceptable air quality levels. The best air quality class shows a perfect linear trend when the number of people is high, while it is slightly disturbed when the number is lower. For the two best air quality classes, and with enough occupants, the following levels of ventilation rate can be determined:

$$
\begin{aligned}
& \mathrm{VR}_{\mathrm{IAQ}, 1}=8.9 \frac{1}{\mathrm{~s}} \frac{1}{\text { pers }} \\
& \mathrm{VR}_{\mathrm{IAQ}, 2}=3.5 \frac{1}{\mathrm{~s}} \frac{1}{\text { pers }}
\end{aligned}
$$




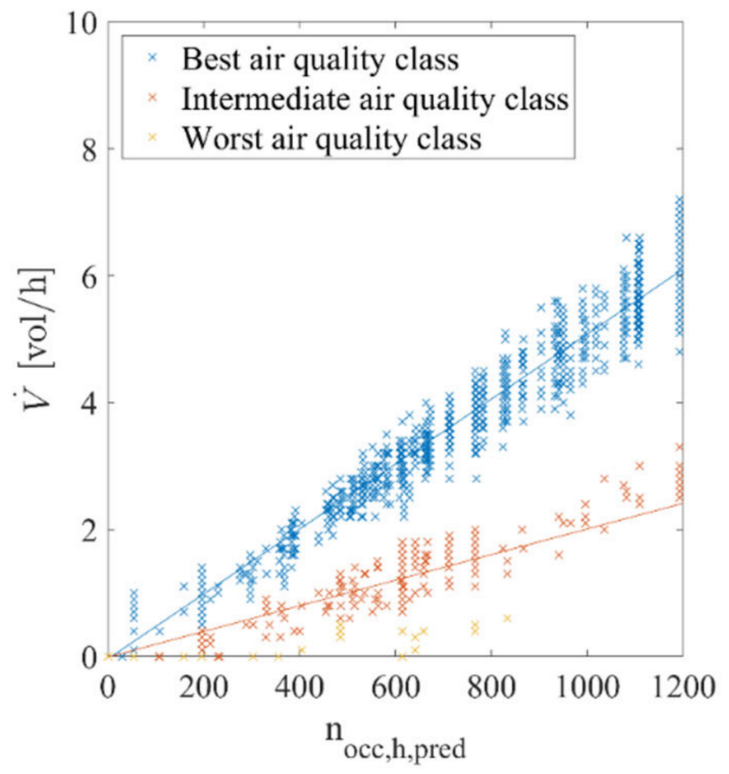

(a)

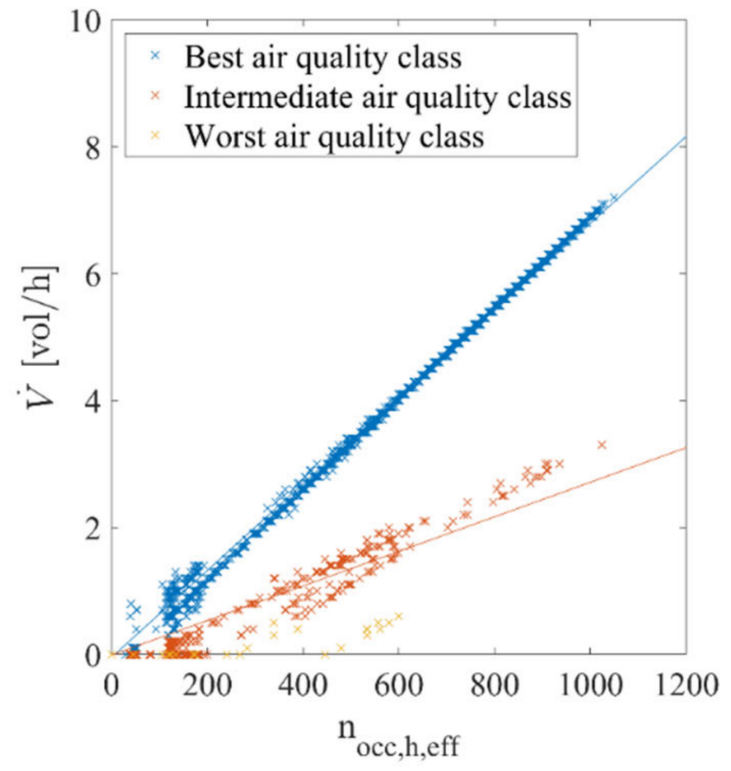

(b)

Figure 8. Ventilation rate as a function of predicted hourly occupancy (a); ventilation rate as a function of "effective" hourly occupancy (b).

The definition of such simple indicators, together with occupants' monitoring, represents a strong method for the determination of the ventilation rates of an air-qualityoriented building. Considering the optimization strategy defined in Section 3.1, and the various operation profiles of the building, the optimization has been performed considering the multi-objective approach. The results of the optimization are reported in Figure 7, and refer to different weighting strategies. The Pareto frontiers for the two targets-global energy demand and annual average PPD—are presented in Figure 9 for static and dynamic weights. The blue line is obtained with static weights ranging from $\mathrm{w}_{\text {comf }}=0.2$ in the lower-right corner to $\mathrm{w}_{\mathrm{comf}}=0.8$ in the upper-left corner. The orange line represents the dynamic weight based on monitoring, defined in Equation (9), with a center of $c_{\text {comf }}=0.5$ and a bandwidth $\left(\mathrm{b}_{\text {comf }}\right)$ ranging from 0.1 near the yellow cross to 0.6 far from it. The yellow cross represents the dynamic weight based on the building schedule, which also represents the limit of $b_{\text {comf }}=0$. The first and most important requirement is that the dynamic weight line lies below the static weight one, which confirms the improvement of the dynamic weight strategy in achieving both comfort and energy saving. Another consideration is that the blue line at its extremes entails unacceptable values for comfort when the weight is shifted to energy saving, and high energy expenses when the weight is shifted to comfort. Comparing the results of a dynamic weight with a bandwidth of $\mathrm{b}_{\text {comf }}=0.4$ to those of a static weight of $\mathrm{w}_{\text {comf }}=0.5$, which have almost the same average PPD, a $10.7 \%$ reduction in energy demands is shown.

Comparing the results of a dynamic weight with a bandwidth of $b_{\text {comf }}=0.6$ to those of a static weight of $\mathrm{w}_{\mathrm{comf}}=0.4$, which have almost the same total energy demand, a $19.2 \%$ reduction in the number of dissatisfied people is shown. These two results represent the maximum improvement that can be obtained for both objectives, comparing dynamic and static weighting strategies.

An important consequence of monitoring the presence of occupants instead of using only the schedule is that, in case of unpredicted occupancy, the monitoring case would identify this and always choose the correct values for temperature, relative humidity and carbon dioxide, while the schedule-based case would be indifferent to this, leading to great discomfort for the unpredicted occupants. 


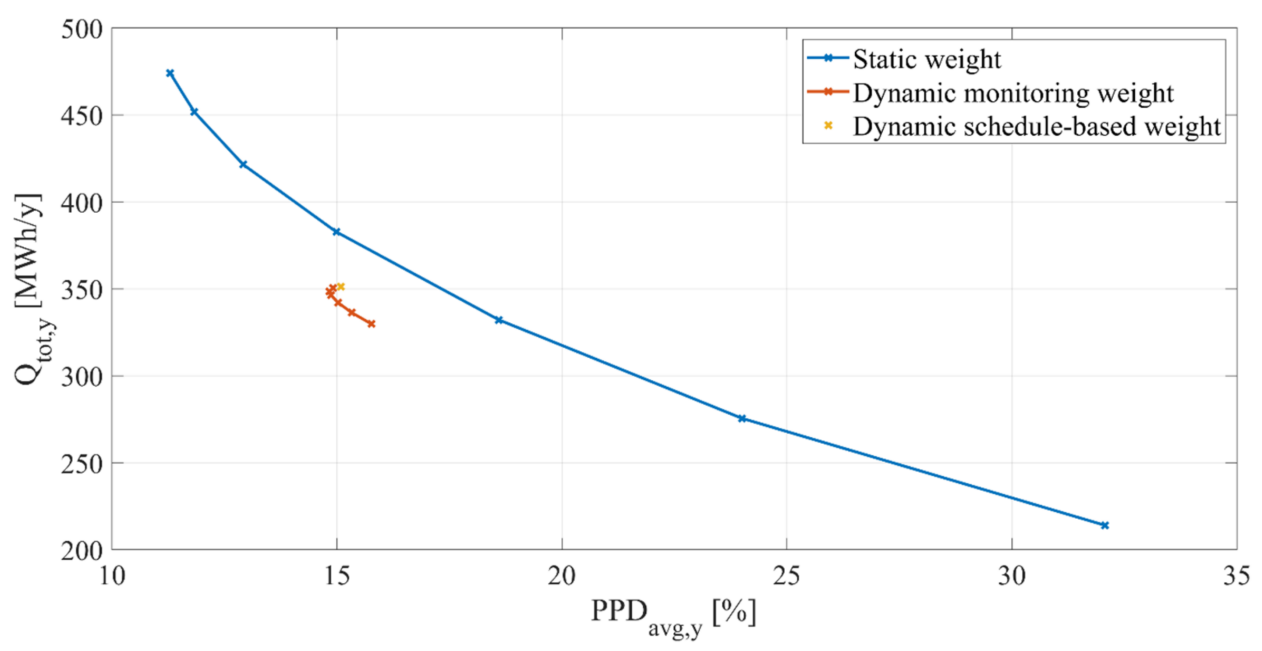

Figure 9. Results of the multi-objective optimization: Pareto frontiers of total energy demand and average percentage dissatisfied for static and dynamic weighting strategies.

The greatest drawback of the monitoring case is the increase in the maximum power requested, especially for heating: the presence of a bandwidth increases the maximum value of the comfort weighting, leading to the selection of a more energy-consuming configuration of the HVAC system. For example, the case of a bandwidth of 0.2 , and the consequent maximum value of the weight of 0.6 , leads to an increase in the heating power of $32.9 \%$. Moving to the comparison between the typical operation suggested by technical standards (according to [30]), and optimized operation, considering ideal control of the HVAC system as a result of the optimization strategy, the main results are reported in Table 4. In particular, by the term "standard operation" we mean the typical operation presented in Section 4 -namely, constant setpoints for the heating season $\left(20^{\circ} \mathrm{C}\right)$ and for the cooling season $\left(26^{\circ} \mathrm{C}\right)$, and a constant ventilation rate evaluated based on peak occupancy; while in case of "optimized operation" of the HVAC system, hourly indoor setpoints and ventilation rates are selected according to the actual level of occupancy, paying more attention to energy consumption when fewer students are in the building. Regarding minimum and maximum temperatures, indoor setpoints are subject to the upper $\left(28^{\circ} \mathrm{C}\right)$ and lower $\left(18^{\circ} \mathrm{C}\right)$ limits reported in international technical standards.

Table 4. Comparison between standard operation and optimized operation.

\begin{tabular}{lcc}
\hline & Standard Operation & Optimized Operation \\
\hline Heating demand $(\mathrm{MWh} / \mathrm{y})$ & 443 & 293 \\
Cooling demand $(\mathrm{MWh} / \mathrm{y})$ & 22 & 18 \\
Total energy demand $(\mathrm{MWh} / \mathrm{y})$ & 507 & 359 \\
Specific energy demand $\left(\mathrm{kWh} / \mathrm{m}^{3}\right)$ & 50.7 & 35.9 \\
Specific energy demand $\left(\mathrm{kWh} / \mathrm{m}^{2}\right)$ & 263 & 186 \\
Average PPD $(\%)$ & 20 & 15 \\
\hline
\end{tabular}

It is shown how optimized dynamic setpoints of temperature, relative humidity and carbon dioxide concentration can lead to great improvements of both energy efficiency and comfort conditions, with achieved reductions of $29.2 \%$ in energy demands (from 507 to $359 \mathrm{MWh} /$ year) and of about $25 \%$ in the modified comfort indicator, PPD (from 20 to about 15). Figures 10 and 11 show the evolution of the daily heating demand (Figure 10) and cooling demand (Figure 11), according to the "standard" and the "optimized" controls, showing the energy advantages of the proposed control strategy. 


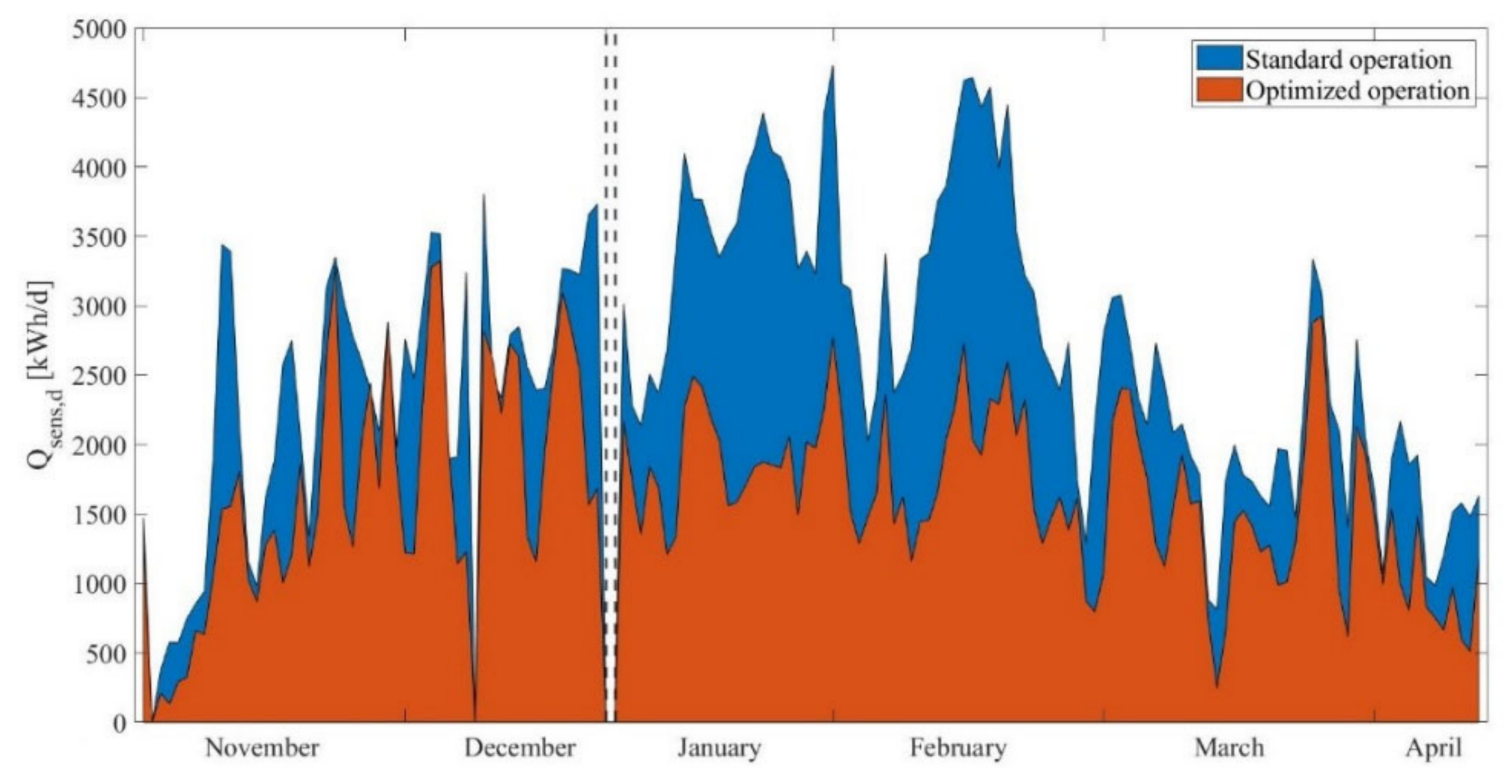

Figure 10. Evolution of the daily heating demand according to the "standard" and the "optimized" controls.

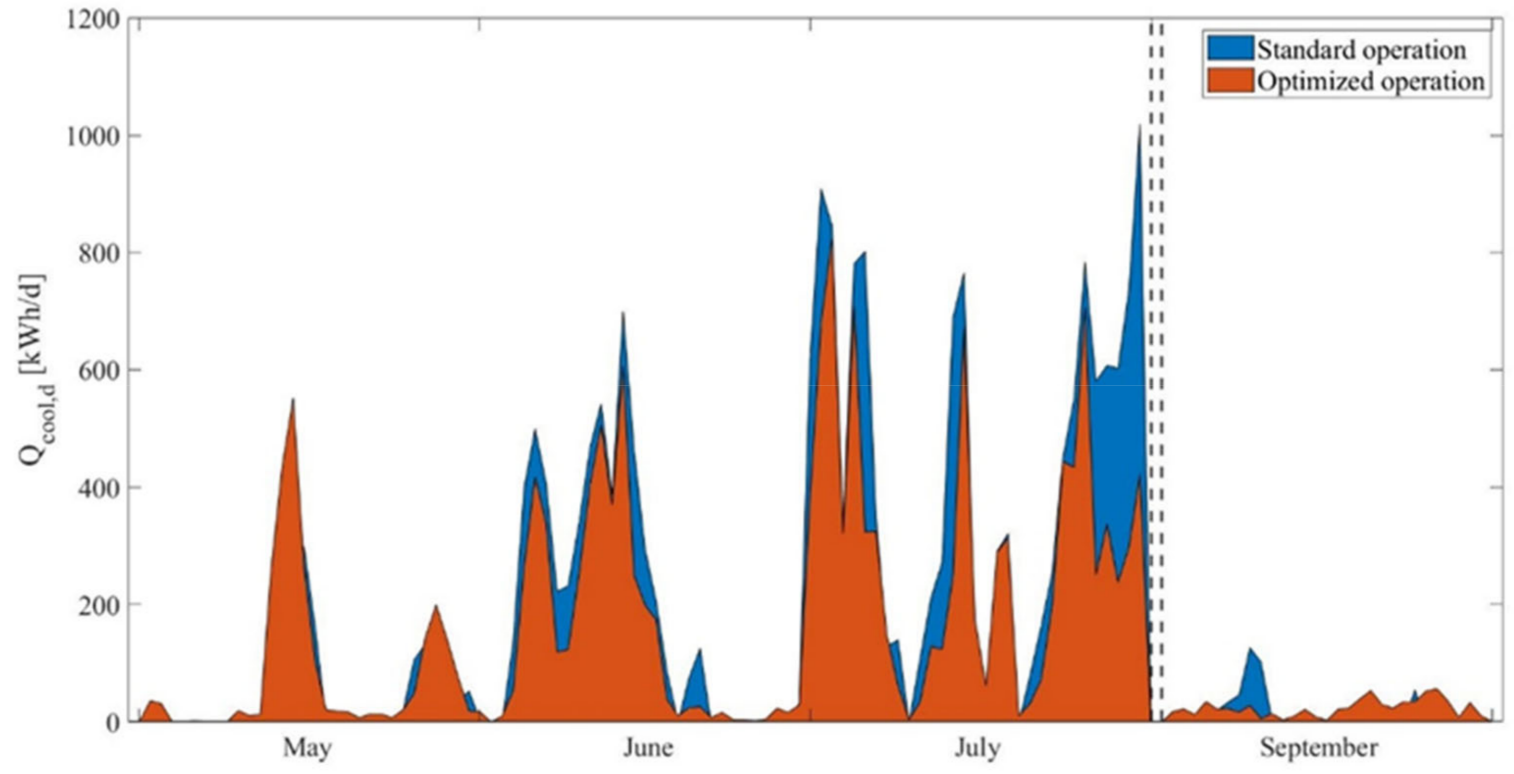

Figure 11. Evolution of the daily cooling demand according to the "standard" and the "optimized" controls.

The results prove that an appropriate HVAC management strategy reduces energy consumption and, at the same, increases the level of comfort (both thermal comfort and air quality). In particular, an accurate analysis of Figures 10 and 11 demonstrates that the control strategy can lead to significant energy savings during the evening hours of the winter season, when low occupancy levels are observed. On the other hand, during highoccupancy moments, comfort can be considered to be the main objective, and the indoor temperature may be increased or decreased further than standard setpoints, reducing energy consumption. The energy savings mainly occur in winter hours with low occupancy, while thermal comfort is maximized during high-occupancy moments. On an annual basis, energy use is reduced, and the comfort level can be increased.

The results obtained are quite interesting in principle, even if accurate forecasts of the climatic conditions and occupancy profiles in the building are required. In addition, the optimization has been performed considering the ideal behavior of the HVAC system. Indeed, the implementation of the proposed optimized control in real HVAC systems 
may represent a critical issue, especially due to the inertia of real HVAC components, which may limit the required dynamicity of setpoints [31]. These aspects could lead to practical criticalities in the implementation phase that could be analyzed and solved with appropriate experimental analyses, to be performed either in situ or with a hardware-in-theloop apparatus emulating the building loads, as in [32]. Furthermore, in real applications, buildings' HVAC system operation will also be constrained by economic aspects, which in some cases may lead to suboptimal operation in terms of energy efficiency, as when demand-response programs are implemented for cost effectiveness.

Considering the problem of COVID-19, at the moment, specific regulations regarding airborne transmission and its consequences on the building control system are not available, for its characterization is still at an embryonic state, and thus it is not considered in this study. However, once a satisfactory development in this field is reached, it will be important to integrate it in the quest for balancing the different objectives, by adding further constraints to the methodology proposed, in order to represent the correct operation and control of the considered buildings [33].

\section{Conclusions}

In this study, a methodology for the optimal operation of a HVAC system focusing both on comfort and energy saving for specific application to educational buildings has been proposed and discussed. The analyzed building does not have a local energy metering system, and the available energy bills also include other facilities. Therefore, we performed a dynamic simulation through a validated thermal network model to obtain the benchmark values of the building's energy needs. The optimized operation has been investigated using the same dynamic model, preserving the coherence of the evaluated energy savings.

In particular, the optimization was obtained by means of a multi-objective approach based on the utility function method. The use of dynamic setpoints, the inclusion and coupling of thermal comfort and air quality, and the use of a stochastic occupancy profile represent steps forward, compared to current design and operation procedures suggested by technical standards, and have shown that there is room for concurrently improving all of the objectives.

In particular, the realistic occupancy profile, based on the monitoring of occupants, has been used actively in defining a dynamic relative importance between the concurrent objectives.

In the discussed case study, represented by an educational building of the University of Pisa, a linear trend with the number of occupants has been proposed for the comfort weighting, and its effects on both of the objectives have been analyzed by means of a Pareto frontier, showing the improvement achieved compared to a static definition of the weight and to common operation suggested by technical standards. The strategy for the optimal control of the HVAC system applied to the test case has shown that it is possible to reduce energy consumption by slightly less than 30\% (shifting from about $500 \mathrm{MWh} /$ year to $350 \mathrm{MWh}$ /year) with respect to current energy usage, without reducing the comfort level of the occupants; this can be obtained via an optimized control system of the HVAC system, and relevant energy savings can be obtained mainly during winter hours with low occupancy profiles (typically during the evening), while comfort can be maximized during high-occupancy moments, when reduced energy consumption can be obtained.

Obviously, though the proposed optimization method can assume a general application, the results obtained in terms of the reduction of energy consumption rely upon the definition of a certain number of constraints. For example, a change in the building's occupancy profile, such as the one ongoing as a consequence of restarting activities at full load after the COVID-19 pandemic, would require the adaptation of the method. In that case, the constraints to be added would be the reduction of occupancy (for example, 25\% of the full occupancy level) and the introduction of any additional constraints imposedfor example, to the minimum required ventilation rate, which would surely increase the specific energy consumption. 
Author Contributions: Conceptualization, A.F., C.B., and D.T.; methodology, A.F., P.C., and D.T.; formal analysis, A.F., L.M, and D.T.; data curation, A.F., L.M., and D.T.; writing-original draft preparation, A.F.; writing-review and editing, A.F. and D.T. All authors have read and agreed to the published version of the manuscript.

Funding: The authors gratefully acknowledge the financial support of the Italian Ministry of Education, University and Research (MIUR), in the framework of the Research Project of Relevant National Interest (PRIN) "The energy FLEXibility of enhanced HEAT pumps for the next generation of sustainable buildings (FLEXHEAT)" (PRIN 2017, Sector PE8, Line A, Grant n. 33).

Institutional Review Board Statement: Not applicable.

Informed Consent Statement: Not applicable.

Data Availability Statement: Not applicable.

Conflicts of Interest: The authors declare no conflict of interest.

\section{Nomenclature}

$\begin{array}{ll}\mathrm{A} & \text { Surface area }\left(\mathrm{m}^{2}\right) \\ \mathrm{C}_{\mathrm{CO}_{2}} & \text { Carbon dioxide concentration } \\ \mathrm{f} & \text { Objective function } \\ \mathrm{G} & \text { Daily solar radiation on horizontal surface }\left(\mathrm{kWh} / \mathrm{m}^{2}\right) \\ \mathrm{n}_{\mathrm{Occ}} & \text { Number of occupants } \\ \mathrm{PMV} & \text { Predicted mean vote } \\ \mathrm{PPD} & \text { Predicted percentage dissatisfied }(\%) \\ \mathrm{Q} & \text { Energy demand }(\mathrm{kWh}) \\ \dot{\mathrm{r}} & \mathrm{CO}_{2} \text { human production rate }\left(\mathrm{m}^{3} / \mathrm{s} / \text { person }\right) \\ \mathrm{RH} & \text { Relative humidity }(\%) \\ \mathrm{t} & \text { Time }(\mathrm{s}) \\ \mathrm{T} & \text { Temperature }\left({ }^{\circ} \mathrm{C}\right) \\ \mathrm{V} & \left.\text { Volume (m }{ }^{3}\right) \\ \dot{\mathrm{V}} & \text { Ventilation rate }\left(\mathrm{m}^{3} / \mathrm{s}\right) \\ \mathrm{VR} & \text { Ventilation rate per person }(\mathrm{l} / \mathrm{s} / \mathrm{person}) \\ \mathrm{w} & \text { Weighting factor of the objective function } \\ \Delta \mathrm{T} \mathrm{m} & \text { Mean temperature difference }(\mathrm{K}) \\ \mathrm{Subscripts} & \\ \mathrm{avg} & \text { Average } \\ \text { comf } & \text { Comfort } \\ \text { cons } & \text { Energy Efficiency } \\ \mathrm{d} & \text { Daily } \\ \mathrm{deum} & \text { Dehumidification } \\ \text { eff } & \text { Effective } \\ \text { ext } & \text { External } \\ \mathrm{h} & \text { Hourly } \\ \mathrm{IAQ} & \text { Indoor air quality } \\ \text { lat } & \text { Latent } \\ \text { pred } & \text { Predicted } \\ \text { sens } & \text { Sensible } \\ \mathrm{TH} & \text { Thermo-hygrometric } \\ \text { tot } & \text { Total } \\ \mathrm{y} & \text { Yearly } \\ \mathrm{BACS} & \text { Building automation and control systems } \\ \mathrm{DHW} & \text { Domestic hot water } \\ \mathrm{HP} & \text { Heat pump } \\ \mathrm{HVAC} & \text { Heating, ventilation and air conditioning } \\ \mathrm{IAQ} & \text { Indoor air quality } \\ \mathrm{MES} & \text { Miscellaneous electric systems } \\ & \end{array}$




\section{References}

1. D'Oca, S.; Hong, T.; Langevin, J. The human dimensions of energy use in buildings: A review. Renew. Sustain. Energy Rev. 2018, 81, 731-742. [CrossRef]

2. Zhao, J.; Lasternas, B.; Lam, K.P.; Yun, R. Loftness, Occupant behavior and schedule modeling for building energy simulation through office appliance power consumption data mining. Energy Build. 2014, 82, 341-355. [CrossRef]

3. Dounis, A.I.; Caraiscos, C. Advanced control systems engineering for energy and comfort management in a building environmentA review. Renew. Sustain. Energy Rev. 2009, 13, 1246-1261. [CrossRef]

4. Wu, J.; Lian, Z.; Zheng, Z.; Zhang, H. A method to evaluate building energy consumption based on energy use index of different functional sectors. Sustain. Cities Soc. 2020, 53, 101893. [CrossRef]

5. Franco, A. Balancing User Comfort and Energy Efficiency in Public Buildings through Social Interaction by ICT Systems. Systems 2020, 8, 29. [CrossRef]

6. Salis, L.C.R.; Abadie, M.; Wargocki, P.; Rode, C. Towards the definition of indicators for assessment of indoor air quality and energy performance in low-energy residential buildings. Energy Build. 2017, 152, 492-502. [CrossRef]

7. Šujanová, P.; Rychtáriková, M.; Mayor, T.S.; Hyder, A. A Healthy, Energy-Efficient and Comfortable Indoor Environment. Rev. Energ. 2019, 12, 1414. [CrossRef]

8. Ma, N.; Aviv, D.; Guo, H.; Braham, W.W. Measuring the right factors: A review of variables and models for thermal comfort and indoor air quality. Renew. Sustain. Energy Rev. 2021, 135, 110436. [CrossRef]

9. Yang, L.; Yan, H.; Lam, J.C. Thermal comfort and building energy consumption implications-A review. Appl. Energy 2014, 115, 164-173. [CrossRef]

10. ISO 7730_Ergonomics of the Thermal Environment Analytical Determination and Interpretation of Thermal Comfort Using Calculation of the PMV and PPD Indices and Local Thermal Comfort Criteria; International Organization for Standardization: Geneva, Switzerland, 2005.

11. EN 16798-3-Energy Performance of Buildings. Ventilation for Buildings. For Non-Residential Buildings. Performance Requirements for Ventilation and Room-Conditioning Systems (Modules M5-1, M5-4); European Committee for Standardization: Bruxelles, Belgium, 2017.

12. Fanger, P.O. Thermal Comfort: Analysis and Applications in Environmental Engineering; Danish Technical Press: Copenhagen, Denmark, 1970; p. 244. [CrossRef]

13. Pérez-Lombard, L.; Ortiz, J.; Pout, C. A review on buildings energy consumption information. Energy Build. 2008, 40, 394-398. [CrossRef]

14. Foucquier, A.; Robert, S.; Suard, F.; Stéphan, L.; Jay, A. State of the art in building modelling and energy performances prediction: A review. Renew. Sustain. Energy Rev. 2013, 23, 272-288. [CrossRef]

15. Schito, E.; Conti, P.; Urbanucci, L.; Testi, D. Multi-objective optimization of HVAC control in museum environment for artwork preservation, visitors' thermal comfort and energy efficiency. Build. Environ. 2020, 180, 1-15. [CrossRef]

16. Lee, D.; Cheng, C.-C. Energy savings by energy management systems: A review. Renew. Sustain. Energy Rev. 2016, 56, 760-777. [CrossRef]

17. Dias Pereira, L.; Raimondo, D.; Corgnati, S.P.; Gameiro Da Silva, M. Energy consumption in schools-A review paper. Renew. Sustain. Energy Rev. 2014, 40, 911-922. [CrossRef]

18. ASHRAE Handbook: Fundamentals, American Society of Heating; Refrigerating and Air-Conditioning Engineers: Atlanta, GA, USA, 2017.

19. Shaikh, P.H.; Nor, N.B.M.; Perumal, N.; Irraivan, E.; Taib, I. A review on optimized control systems for building energy and comfort management of smart sustainable buildings. Renew. Sustain. Energy Rev. 2014, 34, 409-429. [CrossRef]

20. Yang, R.; Wang, L. Multi-objective optimization for decision-making of energy and comfort management in building automation and control. Sustain. Cities Soc. 2012, 2, 1-7. [CrossRef]

21. Hoes, P.; Hensen, J.L.M.; Loomans, M.G.L.C.; de Vries, B.; Bourgeois, D. User behavior in whole building simulation. Energy Build. 2009, 41, 295-302. [CrossRef]

22. Testi, D.; Franco, A.; Conti, P.; Bartoli, C. Clustering of Educational Building Load Data for Defining Healthy and Energy-Efficient Management Solutions of Integrated HVAC Systems. E3S Web Conf. 2020, 197, 1-14. [CrossRef]

23. Dongellini, M.; Naldi, C.; Morini, G.L. Seasonal performance evaluation of electric air-to-water heat pump systems. Appl. Therm. Eng. 2015, 90, 1072-1081. [CrossRef]

24. Franco, A.; Leccese, F. Measurement of $\mathrm{CO}_{2}$ concentration for occupancy estimation in educational buildings with energy efficiency purposes. J. Build. Eng. 2020, 32, 101714. [CrossRef]

25. Franco, A.; Schito, E. Definition of optimal ventilation rates for balancing comfort and energy use in indoor spaces using CO2 concentration data. Buildings 2020, 10, 1-19. [CrossRef]

26. Rao, S. Engineering Optimization. In Theory and Practice, 3rd ed.; John Wiley \& Sons Inc.: Hoboken, NJ, USA, 1996.

27. CTI (Italian Thermotechnical Committee). Italian Typical Meteorological Years. 2016. Available online: https://www.cti2000.it/ index.php? controller=news\&action=show\&newsid=34985 (accessed on 10 May 2021).

28. Queen, J.B.M. Some Methods for classification and Analysis of Multivariate Observations. Proceedings of 5th Berkeley Symposium on Mathematical Statistics and Probability; University of California Press: Berkeley, CA, USA, 1967; pp. $281-297$. 
29. Rousseeuw, P.J. Silhouettes: A graphical aid to the interpretation and validation of cluster analysis. J. Comput. Appl. Math. 1987, 20, 53-65. [CrossRef]

30. EN 16798-1-Energy Performance of Buildings_-Ventilation for Buildings, Part 1: Indoor Environmental Input Parameters for Design and Assessment of Energy Performance of Buildings Addressing Indoor Air Quality, Thermal Environment, Lighting and Acoustics-Module M1-6; European Committee for Standardization: Bruxelles, Belgium, 2019.

31. Dongellini, M.; Piazzi, A.; Morini, G.L. On the Influence of Hydronic Distribution Loop on Energy Performance and Indoor Thermal Comfort for Air-to-Water Heat Pump Systems in Residential Buildings. In Proceedings of the AIP Conference, Isère, France, 8-12 July 2019; pp. 1-11. [CrossRef]

32. Conti, P.; Bartoli, C.; Franco, A.; Testi, D. Experimental Analysis of an Air Heat Pump for Heating Service Using a "Hardware-inThe-Loop" System. Energies 2020, 1, 4498. [CrossRef]

33. Anastasi, G.; Bartoli, C.; Conti, P.; Crisostomi, E.; Franco, A.; Saponara, S.; Testi, D.; Thomopulos, D.; Vallati, C. Optimized Energy and Air Quality Management of Shared Smart Buildings in the COVID-19 Scenario. Energies 2021, 14, 2124. [CrossRef] 